\title{
Consequences of variations in carrying capacity or migration for the perception of Atlantic bluefin tuna (Thunnus thynnus) population dynamics ${ }^{1}$
}

\author{
Jean-Marc Fromentin and Laurence T. Kell
}

\begin{abstract}
Spectacular long-term cycles (around 110 years), independent of human exploitation, have been seen in historical catches of Atlantic bluefin tuna (Thunnus thynnus). Previous studies indicated that such variations could have been generated by contrasting but equally plausible dynamic processes, i.e., changes in carrying capacity or migration. A simulation framework was therefore used to test whether the International Commission for the Conservation of Atlantic Tuna stock assessment model, i.e., a virtual population analysis (VPA), can capture such dynamics. The main outcome is that knowledge of the underlying process is crucial, because distinct hypotheses lead to different population dynamics and contrasting performances of the stock assessment model. The VPA is indeed able to reconstruct accurately the historical stock parameters under the carrying-capacity hypothesis, but not under the migratory hypothesis, for which there is often strong bias (up to 500\%) in absolute values and in trends of spawning stock biomass and $F$. Furthermore, it was shown that $(i)$ different phases between exploitation and long-term cycle can induce contrasting terminal $F$ for a same effort and (ii) that there was considerable confounding between the dynamics and increasing effort (as currently seen). We conclude that it is difficult to infer the actual dynamics on the basis of commercial catch data and that novel fishery-independent observation is needed.
\end{abstract}

Résumé : Les captures historiques du thon rouge atlantique (Thunnus thynnus) présentent de spectaculaires fluctuations à long terme (de l'ordre de 110 ans) qui semblent indépendantes de l'exploitation. Des travaux antérieurs indiquent que les causes de ces variations pourraient résulter de processus dynamiques différents, mais également probables, comme des changements dans la capacité de charge ou de migration. Un modèle de simulation a été utilisé pour tester si le modèle d'évaluation de stock de la CICTA (Commission Internationale pour la Conservation des Thonidés de l'Atlantique), i.e., une analyse des populations virtuelles (APV), peut rendre compte de telles dynamiques. Le principal résultat est que la connaissance des processus sous-jacents est cruciale, parce que des hypothèses distinctes conduisent à des dynamiques de populations différentes et à des performances du modèle d'évaluation contrastées. L'APV est en effet capable d'estimer correctement les principaux paramètres d'intérêt sous l'hypothèse de la capacité de charge, mais pas sous l'hypothèse migratoire, pour laquelle apparaissent fréquemment de forts biais (jusqu'à $500 \%$ ) dans les valeurs absolues et les tendances de la biomasse reproductrice et de $F$. De plus, on constate que $(i)$ des différences de phase entre exploitation et cycle à long terme peuvent générer des $F$ terminaux très différents pour un même effort et (ii) qu'il y avait de fortes interactions entre la dynamique de population et l'effort (surtout si ce dernier est croissant comme cela est actuellement le cas). Nous concluons, qu'il est difficile de déduire la dynamique actuelle à partir des données commerciales de pêche et que des suivis originaux et indépendants de la pêche sont nécessaires.

\section{Introduction}

Fish stocks can fluctuate extensively over a large range of spatial and temporal scales independently of human exploitation (Hjort 1914; Cushing 1995). Such fluctuations are often ascribed to stochastic variations in key processes, such as recruitment, growth, predation, or migration, in relation to environmental modifications (e.g., Lehodey et al. 1997; Bailey 2000; Köster et al. 2005). A recent study on historical catches from the ancestral Atlantic and Mediterranean trap fisheries showed that there had been spectacular long-term fluctuations in bluefin tuna (Thunnus thynnus) catches over the last four centuries (Ravier and Fromentin 2001). These pseudo-cyclic variations of 100-120 years, accounting for more than $50 \%$ of the variance of the time series, were synchronous all around the western Mediterranean and near North Atlantic (i.e., between sites more than $2000 \mathrm{~km}$ apart), so that they were likely to reflect fluctuations in bluefin tuna

Received 4 April 2006. Accepted 17 December 2006. Published on the NRC Research Press Web site at cjfas.nrc.ca on 21 June 2007. J19256

J.-M. Fromentin. IFREMER, Centre de Recherche Halieutique Méditerranéen et Tropical, BP 171, 34203 Sète CEDEX, France. L.T. Kell. ${ }^{2}$ Cefas, Lowestoft Laboratory, Pakefield Road, Lowestoft, Suffolk, NR33 0HT, UK.

${ }^{1 \odot}$ British Crown copyright, 2006.

${ }^{2}$ Corresponding author (e-mail: laurence.kell@ cefas.co.uk). 
population migrating annually in the Mediterranean for spawning (Ravier and Fromentin 2001). Further studies postulated that such long-term fluctuations could alternatively arise from resonant effects, attributable to a combination of stochastic recruitment and long life span (Bjørnstad et al. 2004), or from modifications in migration patterns caused by changes in sea temperature (Ravier and Fromentin 2004).

Whatever the underlying processes, significant fluctuations in carrying capacity or migration patterns can violate various model assumptions used to assess the stock and so affect our perception of stock status (Fromentin et al. 2000; Kell et al. 2000). For instance, the stock assessment of bluefin tuna, which is currently performed by the scientific committee of the International Commission for the Conservation of Atlantic Tuna (ICCAT), considers a single stock for the East Atlantic and Mediterranean Sea. The stock assessment model, based on virtual population analysis (i.e., an ADAPT-VPA approach; Porch 1997), does not reflect the fact that spawning only occurs in specific locations of the Mediterranean Sea. Consequently, potential year-to-year variations in spawning migrations between the East Atlantic and the Mediterranean cannot be quantified, although they may affect catch rates. Furthermore, time series used in stock assessment only extend for 30 years, which is a small fraction of the full natural cycle (100-120 years). Therefore a simulation framework (Kell et al. 2003) was used to evaluate the effect of the potential bias associated with changes in either carrying capacity or migration on the ICCAT stock assessment.

To do so, we modelled a bluefin tuna population displaying either variations in carrying capacity or changes in migration; for each population model, catch and catch per unit effort (CPUE) were sampled and the standard ICCAT stock assessment model was run. This allowed the performances of the stock assessment model to be evaluated for uncertainty about the true dynamic processes.

Although the current study is based on Atlantic bluefin tuna because data on historical catches are available for this population, the study has broad implications for stock assessment and management of other species.

\section{Material and methods}

\section{Simulation model framework}

The simulation framework (Kell et al. 2000, 2003) was used to build $(i)$ an operating model (OM) that represents alternative plausible hypotheses about stock and fishery dynamics, allowing integration of a higher level of complexity and knowledge than used within stock assessment models; (ii) an observation model that describes how pseudo-data are sampled from the operating model; and (iii) a stock assessment and management model to derive estimates of stock status from the pseudo-data (Fig. 1).

Within this framework, three different types of variable are considered. In the operating model, the variables are controlled, i.e., fixed by the operator, so decisions have to be taken on biological parameters. In the observation model, the variables are observed, i.e., deduced from the sampling model. In the stock assessment and management model, the
Fig. 1. Conceptual framework of the simulation model that considers $(i)$ an operating model that represents alternative plausible hypotheses about stock and fishery dynamics, (ii) an observation model that describes how pseudo-data are sampled from the operating model, and (iii) stock assessment and management model to derive estimates of stock status from the pseudo-data.

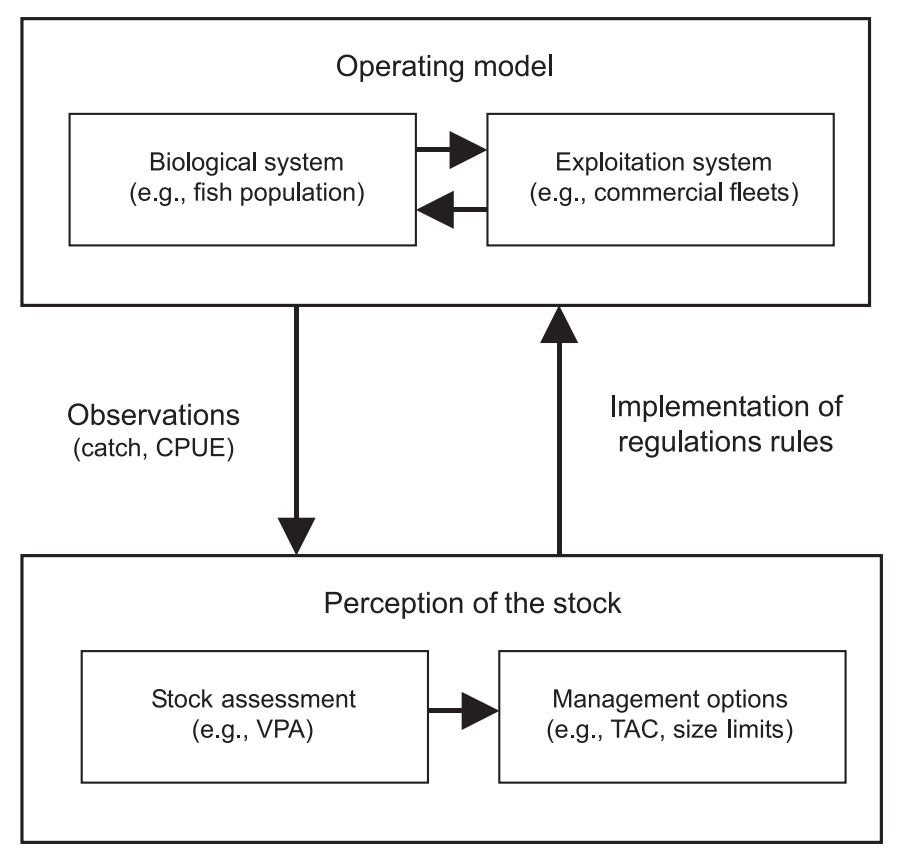

variables are estimated (and represent the dependent variables).

The approach is therefore able to model the full variety of uncertainty characterised by Rosenberg and Restrepo (1994): in the operating model, process error attributable to natural variations in dynamic processes (recruitment, growth, natural mortality, etc.); in the observation model, measurement error generated when collecting observations from a population; in the stock assessment and management estimation, error that arises from trying to model the dynamic process. The approach is also able to model important interactions and feedback processes between the operating model and stock assessment and management model, i.e., the consequences of model mis-specification, because the assumption used within stock assessment may not be the same as in the operating model, and implementation error, because management actions are never implemented perfectly. However, feedback was not included in this case because the objective was to investigate how well current stock assessment assumptions and models used for bluefin tuna capture the dynamics of the stock, not to develop an appropriate management strategy.

\section{Basis of the operating models}

The objective of this study is to use a simulation framework to evaluate whether a stock assessment model based on virtual population analysis (VPA) can capture the dynamics of stocks where ecological processes may generate long-term fluctuations in catches and, in particular, to determine how such variations may affect our perception of stock status and our ability to manage it based on relatively 
short-term time series of data. Therefore an operating model was constructed on the basis of the following age-structured equation:

$$
N_{a, t}=N_{a-1, t-1} \mathrm{e}^{-Z_{a, t}}
$$

where $N_{a, t}$ is the number of fish of age $a$ at time $t, Z_{a, t}$ is the total mortality from age $a-1$ to age $a\left(Z_{a, t}=M_{a}+F_{a, t}\right.$, where $M_{a}$ is the natural mortality at age $a$ and $F_{a, t}$ is the fishing mortality at age $a$ in year $t$ ). Life history traits of the East Atlantic and Mediterranean population are those described in Fromentin and Fonteneau (2001) and ICCAT (2003): (i) annual spawning (1 cohort per year), (ii) 50\% maturity at age 4 , $100 \%$ maturity at ages 5+ (i.e., immature before age 4), (iii) fecundity is linearly proportional to weight, (iv) growth following the von Berttalanffy equation used in the ICCAT working group (with the following parameters: $L_{\infty}=318.85$, $\left.k=0.093, t_{0}=-0.97\right),(v)$ length-weight relationship used in the ICCAT working group $\left(W=2.95 \cdot 10^{-5} \cdot L^{2.899}\right)$, ( $v i$ ) life span of 20 years, and (vii) age-specific, but time-invariant, natural mortality based on tagging experiments on the southern bluefin tuna and used in the ICCAT working group (i.e., $M=0.49$ for age $1,0.24$ for ages $2-5,0.2$ for age $6,0.175$ for age $7,0.15$ for age $8,0.125$ for age 9 , and 0.1 for ages 10-20).

The population dynamics of the OM was further based on a Beverton-Holt stock-recruitment relationship (Beverton and Holt 1957) reparameterised for a given $M$, growth, and maturity at age in terms of steepness $(\tau)$ and virgin biomass $(\gamma)$ (Francis 1992). Steepness is the fraction of the virgin recruitment $\left(R_{\gamma}\right)$ expected when spawning stock biomass (SSB) has been reduced to $20 \%$ of its maximum (i.e., $R=\tau R_{\gamma}$ when $\mathrm{SSB}=\gamma / 5)$ and represents the resilience of the stock to exploitation. In the absence of information on steepness, $\tau$ was set at 0.75 and 0.9 , i.e., a range of values that make biological sense for bluefin tuna.

The expected virgin biomass was arbitrarily set at $10^{6}$ tonnes (t), because the study was intended to provide strategic rather than tactical advice (i.e., the consequences of making different decisions rather than setting specific quotas), and results are presented as relative rather than absolute.

The purpose of the operating model is not to reproduce the entire complexity of bluefin tuna biology and ecology, which would be highly subjective because our knowledge of bluefin tuna ecology relies mainly on a variety of unproven hypotheses (Fromentin and Powers 2005), but to define plausible hypothesis about population dynamics and then to implement the processes of interest, i.e., changes in carrying capacity and migration pattern, to finally measure the effect of the potential bias associated with the underlying assumption of the current ICCAT stock assessment process.

\section{Operating model for carrying capacity $\left(H_{K}\right)$}

This model assumes that the long-term fluctuations observed in trap catches reflect changes in the carrying capacity or virgin biomass $\left(\lambda_{t}\right)$ that are due to a combination of stochastic recruitment and long life span (Bjørnstad et al. 2004). $\lambda_{t}$ is assumed to vary with respect to time as

$$
\lambda_{t}=\sigma \sin (\theta+\delta t)
$$

Fig. 2. Historical catch time series from Atlantic and Mediterranean trap fisheries (thin line) with the smoothing time series (bold line; after Ravier and Fromentin 2001) and fitted sign wave (dotted line).

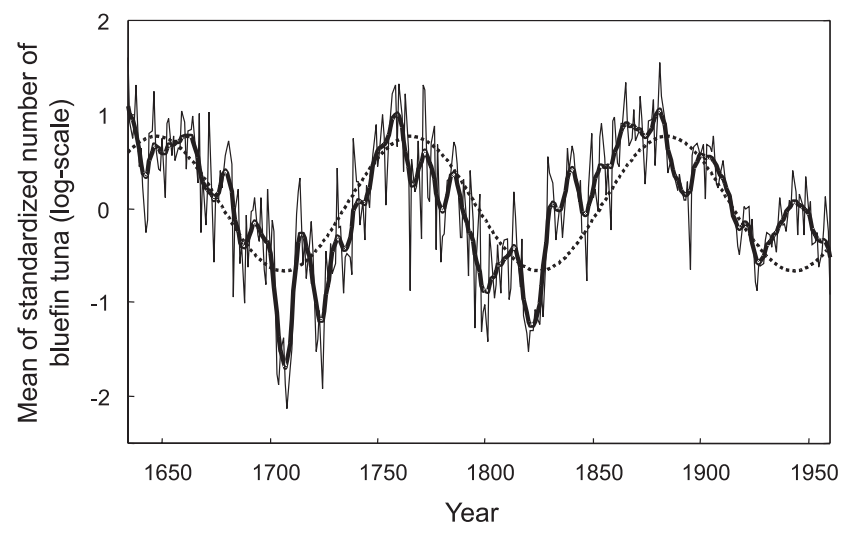

where $\varpi, \theta$, and $\delta$ were chosen to reflect the observed long-term trend in catches (Fig. 2). Note that $\lambda_{t}$ is scaled so as to always be positive.

\section{Operating model for migration $\left(H_{M}\right)$}

According to Ravier and Fromentin (2004), long-term variations in trap catches may alternatively result from changes in migratory patterns that would affect the proportion of mature bluefin tuna entering the Mediterranean Sea each year to reproduce. Knowing that $(i)$ most fishing effort is in the Mediterranean ( $80 \%$ of the total catch occurs in the Mediterranean Sea) and (ii) the vulnerability of bluefin tuna to fishing is much higher in the Mediterranean Sea than in the Atlantic (because it occurs many on spawning aggregations), year-to-year variations in spawning migration between the East Atlantic and the Mediterranean Sea induce concomitant variations in the fraction of the population available to fishing gears (see ICCAT 2007). It may be thus approximated as the proportion of the population being vulnerable to fishing, i.e.,

$$
N_{a+1, t+1}=A_{t} \cdot N_{a, t} \cdot \mathrm{e}^{\left(-M_{a}-F_{a, t}\right)}+\left(1-A_{t}\right) \cdot N_{a, t} \cdot \mathrm{e}^{\left(-M_{a}\right)}
$$

where $A_{t}$ is the proportion of the population available or vulnerable to fishing $\left(1-A_{t}\right.$ is thus equated to the unexploited or cryptic biomass, which is a reasonable simplification acknowledging the relatively low level of effort in the Atlantic in comparison to the Mediterranean). It was assumed that $A_{t}$ was a sinusoidal function of time (constrained to be positive and to vary between $20 \%$ and $80 \%$ ):

$$
A_{t}=\varpi \sin (\theta+\delta t)
$$

where $\varpi, \theta$, and $\delta$ were again chosen to reflect the long-term trend in catches (Fig. 2).

\section{Estimating population trends}

As the dominant signal, i.e., low frequencies, was the process of interest, the smoothed time series of trap catches (Fig. 2) was used to estimate the time-varying population parameters. In both models, the yield was predicted using an age-structured forward projection, with a selectivity pattern similar to the present exploitation (ICCAT 2003). The sum 
Fig. 3. Outputs from the operating model (OM) for a full cycle (110 years) with constant fishing mortality $(F)$ equivalent to $F$ at maximum sustainable yield $\left(F_{\mathrm{MSY}}\right)$ and a steepness of 0.75 . (a) Standardized time series of availability (solid line), virgin biomass (broken line), and effort (dotted-dashed line) for the carrying-capacity hypothesis $\left(H_{K}\right) ;(b)$ same as $(a)$ for the migration hypothesis $\left(H_{M}\right)$;

(c) standardized time series of capture per unit effort (CPUE, solid line) and yield (broken line) for $H_{K}$; $(d)$ same as $(c)$ for $H_{M}$;

(e) standardized time series of spawning stock biomass (solid line), recruitment (broken line), and $F$ (dotted-dashed line) for $H_{K}$;

(f) same as (e) for $H_{M}$.
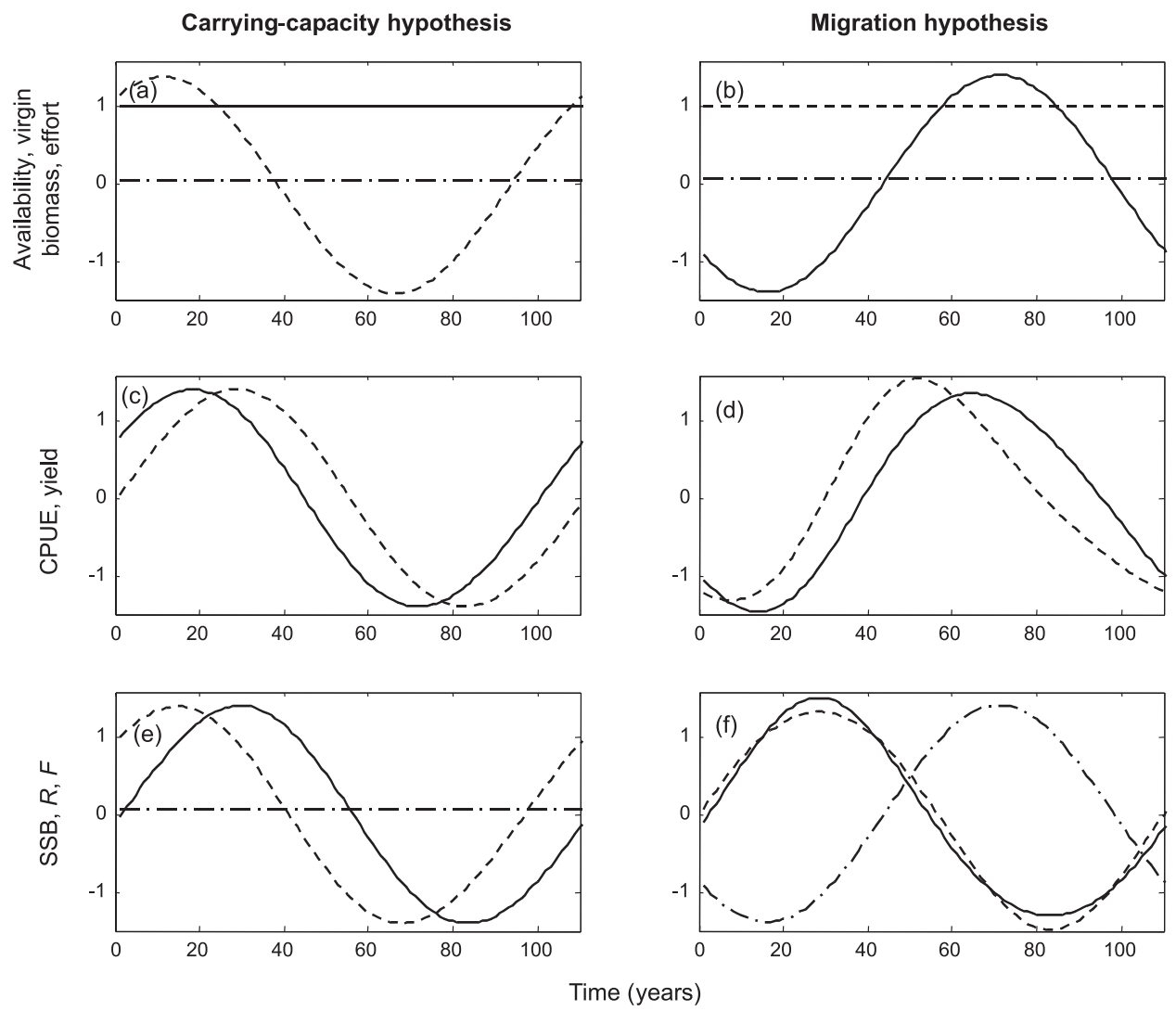

of squares of the difference in the observed trend was scaled so that the difference between the smoothed yield and predicted yields were minimized.

The amplitude of the trend was a given fraction of MSY and fixed so that it was similar under both hypotheses $\left(H_{K}\right.$ and $H_{M}$ ) and in agreement with the variability observed in catches over the 1910-1930 (Ravier and Fromentin 2002) and 1950-1990 periods (i.e., a rough CV of $40 \%$ ).

\section{Sensitivity runs}

Finally, decisions have also to be taken with respect to the historical fishing mortality (relative to MSY) and the starting point of exploitation relative to the natural cycle. For the first point, we considered four different historical $F$ s: constant effort corresponding to $F=50 \%$ of $F_{\mathrm{MSY}}$, constant effort corresponding to $F=F_{\mathrm{MSY}}$, constant effort corresponding to $F=150 \%$ of $F_{\mathrm{MSY}}$, and linear increase in effort corresponding to an increase in $F$ from $50 \%$ of $F_{\mathrm{MSY}}$ to $250 \%$ of $F_{\text {MSY }}$ over a full population cycle (i.e., 110 years).

For the second point, we examined four different starting points (or phases of the cycle), i.e., yield in year 1 was at maximum of the natural cycle, middle of the decreasing trend, minimum of the natural cycle, and middle of the increasing trend.

Monte Carlo simulations, where process and observation errors are modelled as random variables, were also consid-

ered as part of the experimental design. However, stochastic results are presented only in Kell and Fromentin (2007) to evaluate the robustness of the management strategies.

\section{Results}

All the sensitivity runs (including the historical fishing mortality and starting points, as well as the two steepness values) generate 32 simulations for each hypothesis $\left(H_{K}\right.$ and $\left.H_{M}\right)$. Presenting all these 64 simulations will be lengthy and will further create redundancy. Therefore, the results are mainly based on some specific cases to stress the most important outputs, but the results of all the sensitivity runs are finally summarised and compared in the last figure of this section.

\section{Operating models with constant effort}

To illustrate the contrast in dynamics under the two hypotheses for a full cycle of 110 years, the results from a single scenario, with constant effort (equal to $F_{\text {MSY }}$ ) and a steepness of 0.75 , are presented (Fig. 3). Interpretation of the results under $H_{K}$ (where virgin biomass is the fluctuating control variable) are relatively straightforward (Figs. $3 a, 3 c$, $3 e)$. As expected, CPUE, yield, and recruitment $(R)$ vary in synchrony with virgin biomass (note that the catch is confounded with CPUE because effort is constant). An in- 
Fig. 4. Outputs from the operating model (OM) for a full cycle (110 years) with steepness of 0.75 and different levels of fishing mortality $(F)$ : equivalent to $F$ at maximum sustainable yield ( $F_{\mathrm{MSY}}$, solid line), 50\% of $F_{\mathrm{MSY}}$ (broken line), and $150 \%$ of $F_{\mathrm{MSY}}$ (dotted line). (a) $F$ (relative to $F_{\mathrm{MSY}}$ ) against spawning stock biomass (SSB) relative to spawning stock biomass at MSY ( $B_{\mathrm{MSY}}$ ) for carrying-capacity hypothesis $\left(H_{K}\right) ;(b)$ fishing mortality against SSB for migration hypothesis $\left(H_{M}\right) ;(c) F$ (relative to $\left.F_{\mathrm{MSY}}\right)$ against yield (relative to MSY) for $H_{K}$; $(d) F$ against yield for $H_{M}$; $(e) \mathrm{SSB}$ (relative to $B_{\mathrm{MSY}}$ ) against recruitment $\left(R\right.$ relative to $\left.R_{\mathrm{BMSY}}\right)$ for $H_{K}$; (f) SSB against $R$ for $H_{M}$. Shaded curves display for each plot the values that would be expected under equilibrium for the virgin biomass corresponding to the mean value used in the scenarios.

Carrying-capacity hypothesis
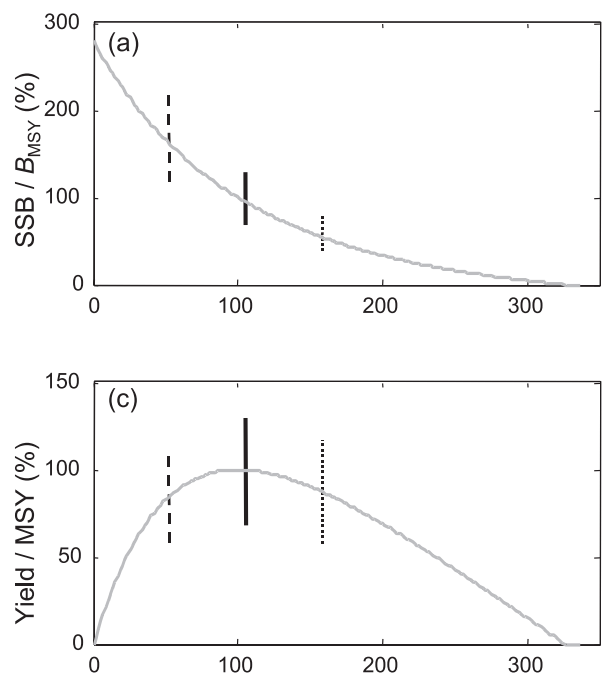

$F\left(\% F_{\mathrm{MSY}}\right)$

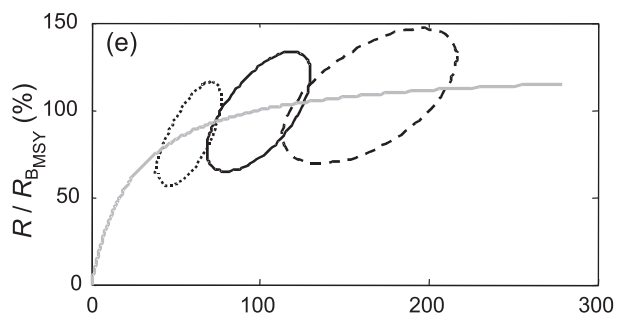

SSB (\% B BSY
Migration hypothesis
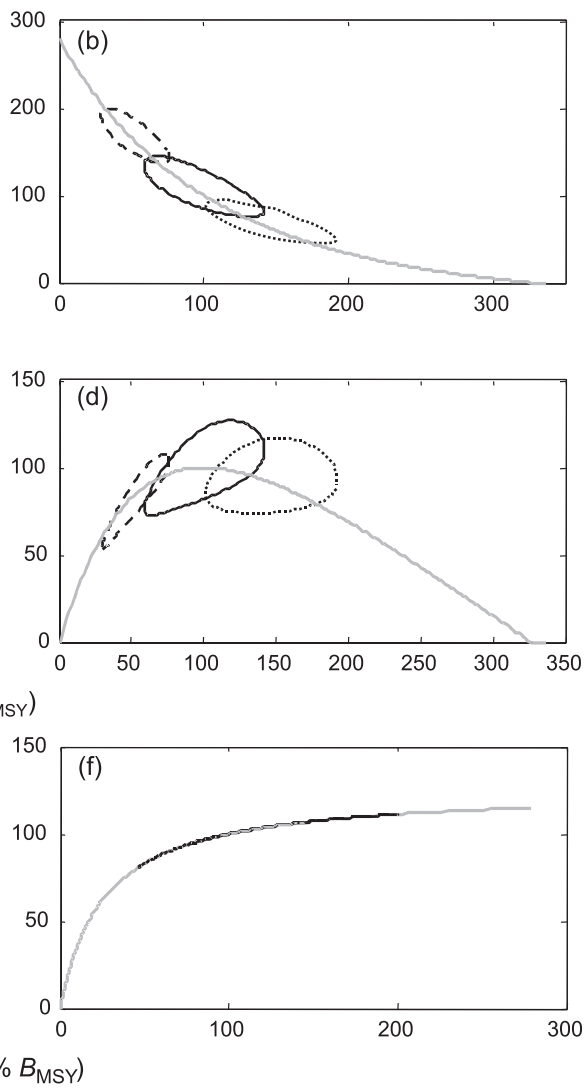

crease or decline in $R$ induces a subsequent increase or decline in SSB and yield with a lag of about 15 years (Figs. $3 c, 3 e$ ). The fact that the yield and CPUE (or catch) are slightly delayed simply reflects changes in the composition of the catches caused by variations in $R$, because older fish weigh more (Fig. $3 c$ ). Under $H_{M}$, when availability is the fluctuating control variable (Fig. $3 b$ ), the results are more complex. Although effort is constant, $F$ fluctuates owing to the varying proportion of the population available to fishing: it increases as the proportion of the population available to fishing increases (Fig. 3f). Variations in fishing mortality and availability are, therefore, synchronous (Figs. 3b, 3f). Also in contrast to the situation with $H_{K}$, synchrony is seen between SSB and $R$ (Fig. 3f). Furthermore, the phases of SSB and $R$ are now in opposition to those of the control variable (and $F$ ). SSB and $R$ are high when the availability to fishing is low, and vice versa. This results from the stock not being in equilibrium, and although fishing mortality is a function of current availability, year-class strength is a function of historic availability. Variations in CPUE (or catch) and yield result from both the fraction being harvested (i.e., availability) and the population size (or SSB), so CPUE and yields peak after the maximum SSB, but before $F$ does. However, the yield is more dependent on SSB than on CPUE (or catch), which generates a slight delay between both variables (Fig. 3d).

Differences between $H_{K}$ and $H_{M}$ are even more obvious when plotting SSB or yield against fishing mortality and recruitment against SSB (for which we still consider a steepness of 0.75 , but the three scenarios with constant effort, i.e., at $50 \%$ of $F_{\mathrm{MSY}}, F_{\mathrm{MSY}}$, and $150 \%$ of $F_{\mathrm{MSY}}$; Fig. 4). Under $H_{K}$, the scatter plots of SSB and yield against fishing mortality display a vertical line, because fishing mortality is a linear function of effort (which is constant) and yield or SSB vary (reflecting long-term variations in virgin biomass and hence in productivity; Figs. $4 a, 4 c$ ). Note that the lag of about 15 years between $R$ and SSB generates a loop of solutions in contrast to what is expected under equilibrium. For a given SSB, there are two values of recruitment (and vice versa). For each of the three efforts, there is a distinct range of possible SSB-R pairs (which move along the expected stock-recruitment curves; Fig. $4 e$ ). In contrast, for $H_{M}$, fishing mortality varies even when effort is constant, and there is a delay between $F$ and SSB (or yield). Consequently, there are two dissimilar and contrasting values of yield and SSB for a given $F$ (Figs. $4 b, 4 d$ ). There is therefore a range of possible $F$-SSB and $F$-yield pairs for a given effort (which also move along the curves of expected values). As SSB and 
Fig. 5. Outputs from the operating model $(\mathrm{OM})$ for a full cycle (110 years) with steepness of 0.75 , increasing fishing mortality $(F$, from $50 \% \mathrm{~F}$ at maximum sustainable yield, $F_{\mathrm{MSY}}$, to $250 \% F_{\mathrm{MSY}}$ ) and two different starting points, i.e., starting at high (solid line) or low (dotted line) carrying capacity or availability. (a) Time series of spawning stock biomass (SSB) relative to spawning stock biomass at MSY $\left(B_{\mathrm{MSY}}\right)$ under carrying-capacity hypothesis $\left(H_{K}\right) ;(b)$ SSB under the migration hypothesis $\left(H_{M}\right)$; $(c)$ time series of yield (relative to MSY) under $H_{K} ;(d)$ yield under $H_{M} ;(c)$ time series of $F$ (relative to $F_{\text {MSY }}$ ) under $H_{K}$; $(d) F$ under $H_{M}$.

Carrying-capacity hypothesis
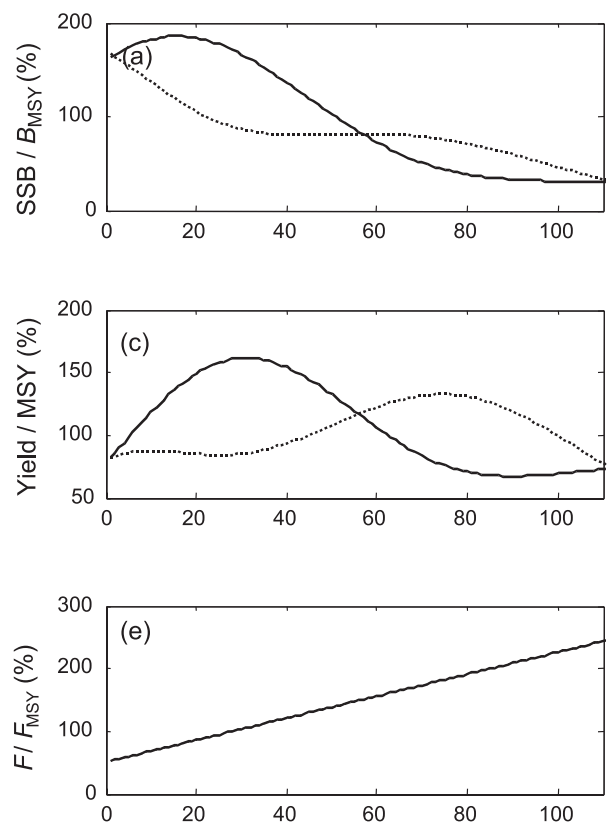

Migration hypothesis
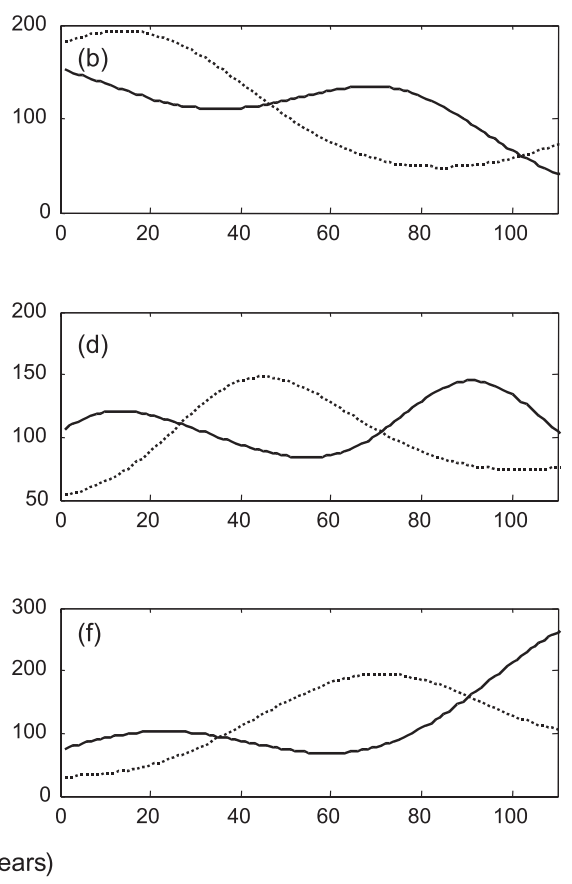

$R$ remain roughly synchronous under $H_{M}$, the relationship between both variables corresponds to that expected under equilibrium (Fig. 4f). A higher steepness of 0.9 does not further change the behaviour and differences between $H_{K}$ and $H_{M}$, but simply moves all the curves along the $x$ and $y$ axes. In conclusion, the underlying mechanisms to the long-term fluctuations in catches really matter, as $H_{K}$ and $H_{M}$ lead to contrasting results, especially regarding $F$ (constant in one case and fluctuating in the other) and the differences of phase between SSB, $R$, yield, and $F$.

\section{Operating models with increasing effort}

The response of the two operating models to a linear increase in effort (leading to an increase in $F$ from $50 \%$ of $F_{\text {MSY }}$ to $250 \%$ of $F_{\text {MSY }}$ ) are explored in Fig. 5 for a steepness of 0.75 and two contrasting starting points, i.e., initially close to a maximum (solid line) and a minimum (broken line) in carrying capacity or availability. Increasing effort alters the long-term fluctuations in carrying capacity or availability that are observed under constant effort (especially in the second part of the cycle, which is generally masked; Figs. $5 a, 5 b, 5 c, 5 d)$. Differences are still seen between $H_{K}$ and $H_{M}$ and also within each hypothesis, depending on the starting conditions. Under $H_{K}$, there is a lag of about 15 years between yield and SSB when effort increases, whereas these are in phase under constant effort (Figs. $3 c$,
$3 e$ ), which is due to year-class effects (Fig. 5a). Differences in starting conditions further generate distinct yield patterns under $H_{K}$ (Fig. $5 c$ ): in one case, yields are relatively stable through time, whereas in the second case, they clearly display a dome-shaped curve (with more variability). Under $H_{M}$, differences in starting conditions are more acute and induce strong differences in the range of $F$. When the simulation starts (and ends) at low availability, fishing mortality is about $F_{\text {MSY }}$ at the end of the series, whereas it exceeds $250 \%$ of $F_{\text {MSY }}$ when starting at high availability (Fig. $5 d$ ). Again this is because availability and SSB are in opposite phase. As $F$ is proportional to availability (see Fig. 3), $F$ remains relatively low for initial and final low availability, because high values of effort are partially compensated for by low values of availability. For initial high availability, greatest effort coincides with greatest availability and generates very high $F$ (Figs. $5 b, 5 f$ ). This makes the final decreasing slope in yield more abrupt (Fig. $5 d$ ). If final SSBs are different $\left(75 \%\right.$ and $40 \%$ of $B_{\mathrm{MSY}}$ when starting at low and high availability, respectively), there are even stronger differences in the terminal trends in SSB (slightly positive in the former case, strongly negative in the latter; Fig. 5b). Finally, there is considerable confounding between the dynamics and increasing effort that makes it difficult to make any inference about the actual dynamics based on commercial catch data. The phases between exploitation and 
Fig. 6. Fishing mortality $(F)$ and spawning stock biomass (SSB) from the operating model (shaded line) and estimated by the virtual population analysis (VPA, broken line) for both carrying-capacity hypothesis $((a)$ and $(c))$ and migration hypothesis $((b)$ and $(d))$, considering

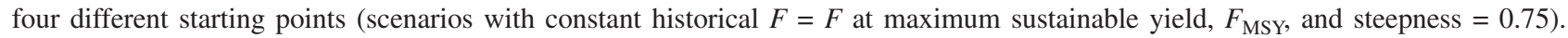

Carrying-capacity hypothesis
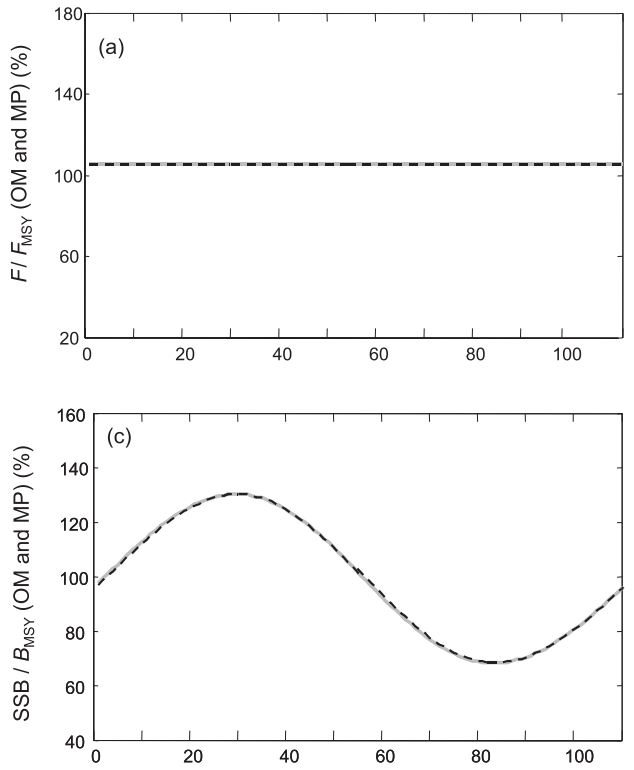

Migration hypothesis
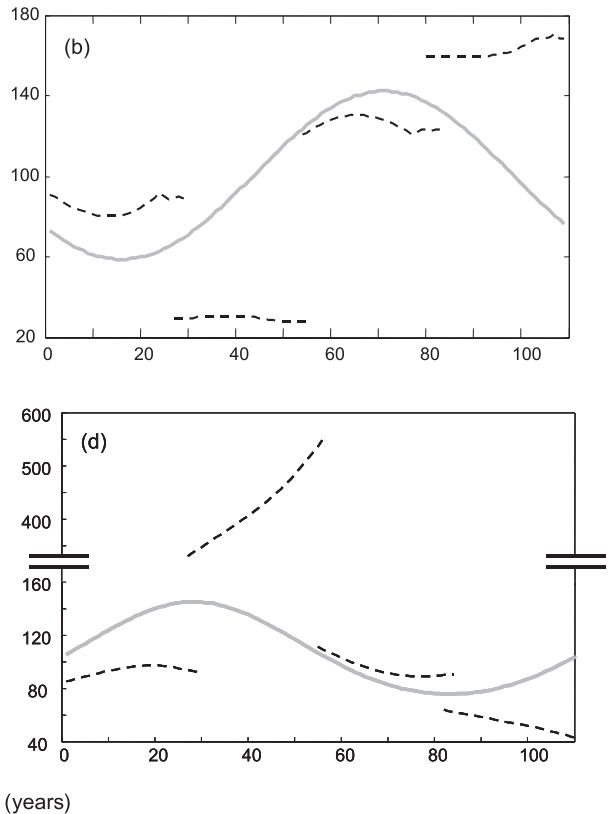

natural cycle further induce contrasting outputs, especially for $H_{M}$, as the terminal $F$ can vary by $250 \%$ for the same effort.

\section{Consequences for stock assessment}

To evaluate the consequences of these two operating models on our perception of stock status, catch-at-age and CPUE were sampled from the operating model (without observation error) for the most recent 30 years. We then used the same ADAPT-VPA used by the ICCAT working group (Porch 1997) to reconstruct the historical stock parameters of interest (i.e., SSB and $F$ ). The performance of VPA to both operating models is firstly evaluated for the scenarios with a constant effort (equivalent to $F_{\mathrm{MSY}}$ ), a steepness of 0.75 , and for four different starting points. In the case of $H_{K}$, VPA is always able to reconstruct the time series of SSB and fishing mortality accurately (both with respect to trends and absolute values; Figs. $6 a, 6 c$ ). However, the reconstruction of the historical time series under $H_{M}$ is more problematic (Figs. $6 b, 6 d$ ), in particular because SSB, yield (and CPUE), and fishing mortality are not synchronous within the OM (see above). Consequently, there is in most cases a mismatch between the time series of auxiliary information (CPUE), catch, SSB, and fishing mortality over the stock assessment period, which induces strong biases in both trend and absolute values (that can even reach up to $500 \%$; Fig. $6 d$ ). The trends in CPUE can, fortuitously, match those of SSB and $F$ over a short period (such as the 30 years of the stock assessment period). In those cases (one in four of the scenarios), the estimates are more satisfactory (Figs. $6 b, 6 d$ ). The other scenarios (with different fishing mortality patterns and higher steepness) are in agreement with the above findings. Finally, the ADAPT-VPA is generally able to reconstruct ac- curately the historical stock parameters under $H_{K}$, but not under $H_{M}$.

Let us finally consider the 64 scenarios (two hypotheses, two steepnesses, four historical $F$ s, and four starting points) to evaluate the main sources of the bias. To do so, we computed the ratio of the VPA to the OM quantities (SSB and $F$ ) of all scenarios (a value close to 1 indicating no bias) through box plots (Fig. 7). The results by hypothesis are clearly dissimilar (Fig. 7a), being unbiased (i.e., equal to 1) for all the cases (no variability) under $H_{K}$, but strongly biased under $H_{M}$, with high variability between cases (>300\% in some cases for SSB). The results by steepness, constant historical $F$ s relative to $F_{\mathrm{MSY}}$, and effort (constant versus increasing) did not display any special patterns (Figs. $7 b, 7 c$, $7 d)$. The results are generally unbiased, except for some cases when $F=50 \%$ or $150 \%$ of $F_{\text {MSY }}$. In other words, differences in steepness, historical $F$ s, and effort (i.e., constant or increasing) do not affect the performances of the VPA, whereas the differences in hypothesis strongly do. The box plots split by phases (or starting points; Fig. 7e) exhibit some strong differences, as the estimates of the VPA (especially those of SSB) are more biased for some phases $(\pi / 2$ and $3 \pi / 2$ ) than others (e.g., 0). Note that for all the scenarios, the estimates of SSB are more biased than those of $F$. In conclusion, the performances of VPA depend firstly on the underlying process that generates long-term fluctuations in catch (i.e., $H_{K}$ or $H_{M}$ ) and secondly on the starting point (i.e., when the exploitation starts along the natural long-term cycle).

\section{Discussion}

The main outcome of this study is that knowledge of the underlying process that generates long-term variations in 
Fig. 7. Box plots of the ratios of spawning stock biomass (SSB) and fishing mortality $(F)$ in operating models (OM) and virtual population analysis (VPA) for all the scenarios (ratios close to 1 indicate no bias or a good performance of the VPA). (a) Scenarios split by hypothesis (carrying-capacity hypothesis, $H_{K}$, versus migration hypothesis, $\left.H_{M}\right) ;(b)$ split by steepness $(\tau=0.75$ and 0.9$) ;(c)$ split by historical fishing mortality intensity (i.e., $50 \%$ of $F$ at maximum sustainable yield ( $\left.\left.F_{\mathrm{MSY}}\right), 100 \% F_{\mathrm{MSY}}, 150 \% F_{\mathrm{MSY}}\right)$; $(d)$ split by constant versus increasing effort; and $(e)$ split by starting points (i.e., phases between exploitation and natural long-term cycle).
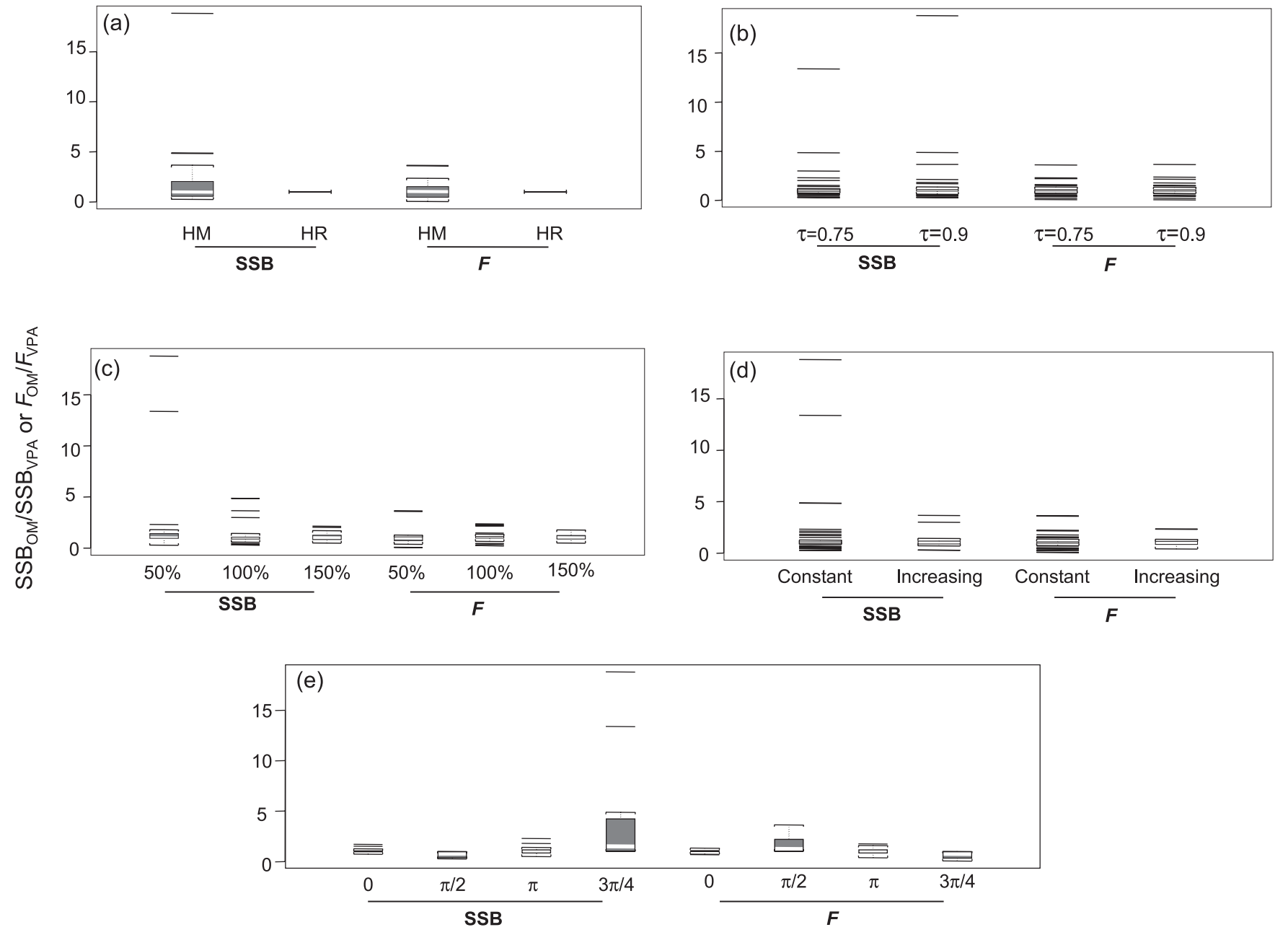

catch is crucial for the current ICCAT assessment procedure because distinct processes (i.e., changes in carrying capacity or in migration) lead to different population dynamics and to contrasting performances of the stock assessment model.

When fluctuations in yield are attributable to changes in carrying capacity $\left(H_{K}\right)$, fishing mortality is proportional to effort and SSB and yield fluctuates in synchrony because variation is driven by recruitment (with a lag of about 15 years). In contrast, under $H_{M}$, fishing mortality fluctuates even when effort is constant, because fishing mortality is proportional to and synchronous with availability. However, SSB and $R$ (which are synchronous in this case) are in opposite phases with $F$ under $H_{M}$. The cycles of yield and CPUE are intermediate between the availability - fishing mortality and SSB-recruitment cycles, because they are driven by both population size and $F$. Consequently, for a given effort, fishing mortality and hence SSB and yield vary. This gap between fishing mortality and stock size is a key feature in understanding differences in the perception of stock status (see below) and the key difference between $H_{M}$ and $H_{K}$.
When fishing effort is increasing, the phases in the dynamic cycle also have a strong effect on the outputs of the operating models. This is because phase determines where in the cycle of SSB the system is, and depending on the phase, changes in SSB and yield can be of quite different magnitudes for the same effort. Under $H_{M}$, the phase strongly influences both the trend and the absolute values of $F$ (and of SSB and yield). When high effort coincides with low availability, $F$ remains relatively low because the high values of effort are partially compensated for by low values of availability, and vice versa. Increasing effort will thus always lead to a depleted stock under $H_{K}$ (as $F$ is directly proportional to effort), but not necessarily under $H_{M}$, because nonavailability of a component of the stock can act as a buffer against overexploitation. This observation is of particular interest with regard to the current exploitation of the Atlantic bluefin tuna, which has strongly increased over the last two decades (Fromentin and Powers 2005). Last ICCAT stock assessments (being partially based on VPA outputs) concluded to a severe overexploitation and overfishing of blue- 
fin tuna that could lead to a rapid fisheries and stock collapse (ICCAT 2003, 2007). If there is very little doubt that current fishing pressure is much too high and unsustainable (Fromentin and Powers 2005; ICCAT 2007), one may thus wonder how this population could have sustained such a long history (i.e., the last 25 years) of heavy exploitation. As we showed, our results suggest that under the migration hypothesis, a high level of exploitation can finally generate moderate $F$ if high values of effort coincide with low availability (but determining the phase of the cycle remains difficult without fishery-independent information). However, this supposition would imply that availability is currently increasing, and therefore $F$ is going to increase sharply and strongly in the coming years (even if effort stays constant). So whatever the underlying mechanism, it appears crucial to significantly reduce fishing effort on bluefin tuna.

The performance of VPA also depends on the underlying process that generates long-term fluctuations in catch. VPA can indeed accurately reconstruct the time series of SSB and fishing mortality (both trends and absolute values) under $H_{K}$, because the catch-at-age matrix and CPUE time series correctly reflect changes in carrying capacity. In contrast, VPA fails in most cases under $H_{M}$, where there is strong bias (up to $500 \%$ ) in the absolute values and also in trends of SSB and $F$. Under $H_{M}$, the perception of the stock is generally erroneous, because availability to fishing remains unknown (neither the catch-at-age matrix nor the CPUE time-series can reflect such changes) and because the process induces a strong delay between fishing mortality and SSB (or recruitment). Indeed, population dynamics models assume that stock size varies in synchrony with fishing mortality because all individuals of a given stock are supposed to be equally vulnerable to fishing (Hilborn and Walters 1992). When postulating potential changes in availability (which has been also assumed for other tuna species; see Fonteneau et al. 1998), this hypothesis is violated, which makes classical population models unreliable.

The recent ICCAT reports stressed the potential biases in VPA outputs because of strong uncertainties in catch-at-age and CPUE indices (ICCAT 2003, 2007). Our results indicated that the VPA performances could be further seriously impaired if the long-term variations in catches are due to changes in migration or availability. It is therefore crucial to understand which underlying process induces long-term variations in catches to be able to recreate population dynamics, which primarily depends on our ability to collect novel fishery-independent observations as, in the case of bluefin tuna, data and knowledge are currently much more limiting than models. However, collecting fisheries-independent information on recruitment and SSB, which is regularly carried out for various pelagic or demersal fish stocks (e.g., Pennington and Strømme 1998; Gudmundsson 2004), is difficult for Atlantic bluefin tuna because of the species' highly migratory nature, wide spatial distribution, and complex, but still largely unknown, behaviour (Mather et al. 1995; Royer et al. 2004; Schick et al. 2004). New technologies have nonetheless opened avenues of great interest to tackle such a challenge. The most popular is undoubtedly electronic tagging (e.g., Block et al. 2005), which in the near future (if effort is enforced in the Mediterranean Sea) could allow estimation of migratory behaviour. The combination of a fixed hydrophone array across the Gibraltar Strait with acoustic tags is another (audacious) option. Such a system, which would be closer to those recently set up to track Atlantic salmon (e.g., Lacroix and McCurdy 1996), could allow the quantification of the migratory flux of bluefin tuna through Gibraltar during the spawning season. Fromentin and Powers (2005) further suggested that genetic tagging (see, e.g., Palsbøll et al. 1997) might have potential for application to bluefin tuna to directly estimate population parameters, especially $F$.

The delay between $R$ and SSB under $H_{K}$ means that for a given fishing mortality, there is a pair of yields and SSB that can affect the consequences of employing biological reference points based on fishing mortality, SSB, and yield (Cook and Heath 2005; Kell et al. 2005a, 2005b). Delays between $F$, yield, and SSB (and recruitment) under $H_{M}$ should also strongly affect estimation of biological reference points. Because of these various lags between $\mathrm{SSB}$ and $R$ or $F$, long-term variations in carrying capacity or migration pattern are likely to influence our capacity to predict future state (e.g., over 15 years) from current perceived status (even if the perception remains unbiased). The evaluation of the performance of VPA stock assessment methods to provide accurate predictions and biological reference points (BRPs) is part of the evaluation of management process, which is the purpose of Kell and Fromentin (2007). More precisely, the performances of BRPs are compared under both hypotheses $\left(H_{K}\right.$ and $\left.H_{M}\right)$ with respect to their ability to provide accurate estimates of MSY, $F_{\mathrm{MSY}}$, and $B_{\mathrm{MSY}}$ and to assess stock status and exploitation level relative to them. In addition, the performance of contrasting management strategies in the face of uncertainty about the true dynamic processes is evaluated.

\section{Acknowledgements}

This paper was prepared with funding support provided by the UK Department for Environment, Food and Rural Affairs (DEFRA, under contract M0322) for LTK and by the European Commission Research Directorates through the EU FP5 project FEMS: Framework for Evaluation of Management Strategies (contract Q5RS-2002-01824). The authors thank Dr. A.I.L. Payne for comments and suggestions on early and final drafts.

\section{References}

Bailey, K.M. 2000. Shifting control of recruitment of walleye pollock Theragra chalcogramma after a major climatic and ecosystem change. Mar. Ecol. Progr. Ser. 198: 215-224.

Beverton, R.J.H., and Holt, S.J. 1957. On the dynamics of exploited fish populations. Fish. Investig. London Ser. 2, No. 19.

Bjørnstad, O., Nisbet, R.M., and Fromentin, J.-M. 2004. Trends and cohort resonant effects in age-structured populations. J. Anim. Ecol. 73(6): 1157-1167.

Block, B.A., Teo, S.L.H., Walli, A., Boustany, A., Stokesbury, M.J., Farwell, C.J., Weng, K.C., Dewar, H., and Williams, T.D. 2005. Electronic tagging and population structure of Atlantic bluefin tuna. Nature (London), 434: 1121-1127. 
Cook, R.M., and Heath, M.R. 2005. The implications of warming climate for the management of North Sea demersal fisheries. ICES J. Mar. Sci. 62(7): 1322-1326.

Cushing, D.H. 1995. Population production and regulation in the sea: a fisheries perspective. Cambridge University Press, Cambridge, UK.

Fonteneau, A., Gascuel, D., and Pallares, P. 1998. Vingt-cinq ans d'évaluation des ressources thonières de l'Atlantique: quelques réflexions méthodologiques. Coll. Vol. Scient. Pap. ICCAT, 50: 523-561.

Francis, R.I.C.C. 1992. Use of risk analysis to assess fishery management strategies: a case study using orange roughy (Hoplostethus atlanticus) on the Chatham Rise, New Zealand. Can. J. Fish. Aquat. Sci. 49(5): 922-930.

Fromentin, J.-M., and Fonteneau, A. 2001. Fishing effects and life history traits: a case-study comparing tropical versus temperate tunas. Fish. Res. 53(2): 133-150.

Fromentin, J.-M., and Powers, J. E. 2005. Atlantic bluefin tuna: population dynamics, ecology, fisheries and management. Fish Fish. 6(4): 281-306.

Fromentin, J.-M., Fonteneau, A., and Farrugio, H. 2000. Biological reference points and natural long-term fluctuations: the case of the eastern Atlantic bluefin tuna. Coll. Vol. Sci. Pap. ICCAT, 51: 2072-2083.

Gudmundsson, G. 2004. Time-series analysis of abundance indices of young fish. ICES J. Mar. Sci. 61(2): 176-183.

Hilborn, R., and Walters, C.J. 1992. Quantitative fisheries stock assessment: choice, dynamics and uncertainty. Chapman \& Hall, New York.

Hjort, J. 1914. Fluctuations in the great fisheries of northern Europe. Viewed in the light of biological research. Rapp. Proc.-Verb. Réun. Cons. Perm. Int. Explor. Mer, 20: 1-228.

International Commission for the Conservation of Atlantic Tuna. 2003. Report of the 2002 Atlantic bluefin tuna stock assessment session. Coll. Vol. Sci. Pap. ICCAT, 55: 710-937.

International Commission for the Conservation of Atlantic Tuna. 2007. Report of the 2006 Atlantic bluefin tuna stock assessment session. Coll. Vol. Scient. Pap. ICCAT, 60. In press.

Kell, L.T., and Fromentin, J.-M. 2007. Evaluation of the robustness of maximum sustainable yield based management strategies to variations in carrying capacity or migration pattern of Atlantic bluefin tuna (Thunnus thynnus). Can. J. Fish. Aquat. Sci. 64: 837-847.

Kell, L.T., Fromentin, J.-M., Gauthiez, F., and Restrepo, V. 2000. A simulation framework to evaluate management strategies for Atlantic tunas: a preliminary example based on East Atlantic bluefin tuna. Coll. Vol. Sci. Pap. ICCAT, 51: 2095-2116.

Kell, L.T., Die, D., Restrepo, V., Fromentin, J.-M., Ortiz de Zarate, V., and Pallares, P. 2003. An evaluation of management strategies for Atlantic tuna stocks. Sci. Mar. 67(Suppl. 1): 353-370.

Kell, L.T., Pilling, G.M., Kirkwood, G.P., Pastoors, M., Mesnil, B., Korsbrekke, K., Abaunza, P., Aps, R., Biseau, A., and Kunzlik,
P. 2005a. An evaluation of the implicit management procedure used for some ICES roundfish stocks. ICES J. Mar. Sci. 62(4): 750-759.

Kell, L.T., Pilling, G.M., and O’Brien, C.M. 2005b. Implications of climate change for the management of North Sea cod (Gadus morhua). ICES J. Mar. Sci. 62(7): 1483-1491.

Köster, F.W., Möllmann, C., Hinrichsen, H.-H., Wieland, K., Tomkiewicz, J., Kraus, G., Voss, R., Makarchouk, A., MacKenzie, B,R., St. John, M.A., Schnack, D., Rohlf, N., Linkowski, T., and Beyer, J.E. 2005. Baltic cod recruitment - the impact of climate variability on key processes. ICES J. Mar. Sci. 62: 14081425.

Lacroix, G.L., and McCurdy, P. 1996. Migratory behaviour of post-smolt Atlantic salmon during initial stages of seaward migration. J. Fish Biol. 49: 1086-1101.

Lehodey, P., Bertignac, M., Hampton, J., Lewis, A., and Picaut, J. 1997. El Niño Southern Oscillation and tuna in the western Pacific. Nature (London), 389: 715-718.

Mather, F.J., Mason, J.M., and Jones, A.C. 1995. Historical document: life history and fisheries of Atlantic bluefin tuna. NOAA Technical Memorandum No. NMFS-SEFSC-370.

Palsbøll, P.J., Allen, J., Bérubé, M., Clapham, P.J., Feddersen, T.P., Hammondk, P.S., Hudson, R.R., Jørgensen, H., Katona, S., Larsen, A.H., Larsen, F., Lien, I.J., Mattila, D.K., Sigurjonnsson, J., Sears, R., Smith, T., Sponer, R., Stevick, P., and Øien, N. 1997. Genetic tagging of humpback whales. Nature (London), 388: 767-769.

Pennington, M., and Strømme, T. 1998. Surveys as a research tool for managing dynamic stocks. Fish. Res. 37(1-3): 97-106.

Porch, C.E. 1997. A user's manual for VPA-2BOX version 2.0. National Marine Fisheries Service, Miami, Fla.

Ravier, C., and Fromentin, J.-M. 2001. Long-term fluctuations in the eastern Atlantic and Mediterranean bluefin tuna population. ICES J. Mar. Sci. 58(6): 1299-1317.

Ravier, C., and Fromentin, J.-M. 2002. Eastern Atlantic bluefin tuna: what we learnt from historical time-series of trap catches. Coll. Vol. Sci. Pap. ICCAT, 54: 507-516.

Ravier, C., and Fromentin, J.-M. 2004. Are the long-term fluctuations in Atlantic bluefin tuna (Thunnus thynnus) population related to environmental changes? Fish. Oceanogr. 13(3): 145-160.

Rosenberg, A.A., and Restrepo, V.R. 1994. Uncertainty and risk evaluation in stock assessment advice for U.S. marine fisheries. Can. J. Fish. Aquat. Sci. 51(12): 2715-2720.

Royer, F., Fromentin, J.-M., and Gaspar, P. 2004. Association between bluefin tuna schools and oceanic features in the western Mediterranean Sea. Mar. Ecol. Progr. Ser. 269: 249-263.

Schick, R.S., Goldstein, J., and Lutcavage, M.E. 2004. Bluefin tuna (Thunnus thynnus) distribution in relation to sea surface temperature fronts in the Gulf of Maine (1994-96). Fish. Oceanogr. 13(4): 225-238. 